International Journal of Pure and Applied Mathematics

Volume 115 No. 3 2017, 561-575

ISSN: 1311-8080 (printed version); ISSN: 1314-3395 (on-line version)

url: http://www.ijpam.eu

doi: 10.12732/ijpam.v115i3.10

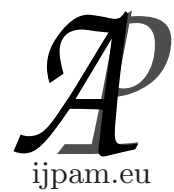

\title{
HEAT ABSORPTION BY HEAT-TRANSFER AGENT IN A FLAT PLATE SOLAR COLLECTOR
}

\author{
Murat M. Kunelbayev ${ }^{1 \S}$, Emil Sh. Gaysin ${ }^{2}$, \\ Vladimir V. Repin ${ }^{3}$, Marat M. Galiullin ${ }^{4}$, Karina N. Abdrakhmanova ${ }^{5}$ \\ ${ }^{1}$ Department of Physics \\ Kazakh State Women's Teacher Training University \\ 99 Aiteke bi Street, Almaty, 050006, KAZAHSTAN \\ ${ }^{2}$ Department of Transport and Storage of Oil and Gas \\ Ufa State Petroleum Technological University \\ 1 Kosmonavtov Street, Ufa, \\ Republic of Bashkortostan, 450062, RUSSIA \\ ${ }^{3}$ Department of Industrial Heat Power Engineering \\ Ufa State Petroleum Technological University \\ 1 Kosmonavtov Street, Ufa, \\ Republic of Bashkortostan, 450062, RUSSIA \\ ${ }^{4}$ Department of Mathematics \\ Ufa State Petroleum Technological University \\ 1 Kosmonavtov Street, Ufa, \\ Republic of Bashkortostan, 450062, RUSSIA \\ ${ }^{5}$ Department of Industrial Safety and Labor Protection \\ Ufa State Petroleum Technological University \\ 1 Kosmonavtov Street, Ufa, \\ Republic of Bashkortostan, 450062, RUSSIA
}

\footnotetext{
Abstract: The authors consider heat absorption by heat-transfer agent in a flat plate solar collector as well as construction of such solar collectors. At given effective channel

Received: $\quad$ May 29, 2017

Revised: $\quad$ July 2, 2017

Published: July 27, 2017

$\S_{\text {Correspondence author }}$

(c) 2017 Academic Publications, Ltd. url: www.acadpubl.eu
} 
diameter, thermal efficiency of the plant grows as $\phi$ (the ratio of the channel diameter to the distance between channel axes) increases. The upper limit of $\phi$ is restricted by the given temperature of heated water output. It reaches its peak at $t_{k}=t_{\text {out }}^{w}$ because $q_{n k}^{\prime}>>q_{c n}$ ( $t_{k}$ is water temperature at the upper part of solar collector, $q_{n k}^{\prime}$ is the output heat flow and $q_{c n}$ is the input heat flow). All other factors being the same, the thermal efficiency of the plant is reduced but slightly as channel diameter grows from $14 \mathrm{~mm}$ to $30 \mathrm{~mm}$. The effect becomes stronger as channel diameter is decreased below $14 \mathrm{~mm}$. As water temperature is decreased at the plant output, the thermal efficiency is increased and shifts toward growing $\phi$ values. Under the normal operating conditions of a flat plate solar collector, the maximum practically achievable value of thermal efficiency at $t=60^{\circ} \mathrm{C}$ is 0.28 , and it grows to 0.4 as the temperature of output water is reduced by $10^{\circ} \mathrm{C}$.

AMS Subject Classification: 74F05, 58J35, 81T28

Key Words: solar radiation, thermal efficiency, flat plate solar collector, angle of solar collector

\section{Introduction}

The EC Fund of housing involves $25 \%$ houses with solar collectors on their roofs (that supply house heating and hot water). This is the most complicated sector of housing [1] whose power efficiency is priority for energy modernization [2] and [3]. The additional technical elements and promising proposals for market updating are given by development of new solar heat supply systems [4], [5] and $[6]$.

To provide hot water for residential use as well as for house heating and cooling, solar collectors are placed at the vertical surfaces $(30 \%$ the total number of collectors) [6]. Several commercial applications of solar collectors for repairs as well as some available products for solar thermal power plants are known [7]. The idea of applying metal absorbers in solar thermal power plants for solar heating of houses was developed and studied in the European project [8]. A heater prototype and a new approach were developed in the European project to optimize arrangement of absorber with an aluminum solar collector [9].

Knowing the radiative and convective heat transfer coefficients of collector, one can correctly simulate the heat loss factor [10]. 


\section{Methods of Calculations}

If the quantum of water heated per 1 hour by $1 \mathrm{~m}^{2}$ of glassed surface of solar collector is $1 \mathrm{~kg}$, heat capacity of water $C$ is $4.19 \cdot 10^{3} \mathrm{~kJ} / \mathrm{kg}^{\circ} \mathrm{C}$ and temperature of water flowing through tube input (output) is $t_{i n}^{w}\left(t_{\text {out }}^{w}\right)$, then the quantity of heat absorbed by water is

$$
q_{a b s}=\operatorname{Re} C\left(t_{i n}^{w}-t_{o u t}^{w}\right)
$$

( $R e$ is the Reynolds number). On the other hand, this quantity of heat is transferred from the surface of solar collector tubes by radiation and convection. The total heat flow consists of the following components:

1) Heat radiated on the tubes by the inner glass surface:

$$
q_{s t}=A\left[\left(\frac{T_{c 1}}{100}\right)^{4}-\left(\frac{T_{c}}{100}\right)^{4}\right]
$$

2) Heat radiated on the channels by the free part of the heat receiver:

$$
Q_{s k}=A\left[\left(\frac{T_{k}}{100}\right)^{4}-\left(\frac{T_{c}}{100}\right)^{4}\right]
$$

3) Heat of the direct solar radiation absorbed by the surface of heat-removing channels:

$$
q_{n k}=E \perp a_{s t} \varepsilon_{k}
$$

4) Heat transmitted by convection from air in the solar collector to the surface of heat-removing channels:

$$
q_{b k}=a_{c} \pi \phi\left(T_{c}-T_{k}\right)
$$

Here $a_{c}$ is calculated by the following expression:

$$
a_{c}=1.10 \cdot\left(\frac{T_{c}-T_{k}}{d_{e k}}\right)^{\frac{1}{4}}
$$

Substitution of $a_{c}$ from Eq. (6) in Eq. (5) gives:

$$
q_{b k}=\frac{1.1 \pi \phi}{d^{\frac{1}{4}}}\left(T_{c}-T_{k}\right)^{\frac{1}{4}}
$$

or 


$$
q_{b k}=A_{1} \cdot 316 \cdot\left(\frac{T_{c}}{100}-\frac{T_{k}}{100}\right)^{\frac{1}{4}}
$$

where

$$
A_{1}=\frac{1.1 \pi \phi}{d_{e k}^{\frac{1}{4}}}
$$

\section{Results and Discussion}

Table 1. The $A_{1}$ values at different $\phi$ and $d\left(C_{e q}\right.$ is the equivalent specific heat).

\begin{tabular}{|c|c|c|c|c|c|c|c|c|c|}
\hline$C_{e q} / \phi$ & 00 & 0.08 & 0.13 & 0.18 & 0.23 & 0.28 & 0.33 & 0.38 & 0.43 \\
\hline 8 & 0.00 & 0.164 & 0.267 & 0.369 & 0.473 & 0.575 & 0.678 & 0.783 & 0.885 \\
\hline 13 & 0.00 & 0.146 & 0.236 & 0.328 & 0.418 & 0.510 & 0.599 & 0.692 & 0.781 \\
\hline 18 & 0.00 & 0.138 & 0.224 & 0.301 & 0.396 & 0.468 & 0.552 & 0.635 & 0.720 \\
\hline 23 & 0.00 & 0.125 & 0.204 & 0.282 & 0.360 & 0.438 & 0.518 & 0.596 & 0.677 \\
\hline 23 & 0.00 & 0.120 & 0.195 & 0.271 & 0.345 & 0.421 & 0.516 & 0.570 & 0.645 \\
\hline 33 & 0.00 & 0.115 & 0.187 & 0.260 & 0.332 & 0.405 & 0.475 & 0.548 & 0.621 \\
\hline 38 & 0.00 & 0.112 & 0.180 & 0.250 & 0.319 & 0.390 & 0.459 & 0.529 & 0.600 \\
\hline 43 & 0.00 & 0.107 & 0.175 & 0.243 & 0.310 & 0.378 & 0.445 & 0.512 & 0.580 \\
\hline
\end{tabular}

It is possible to make considerably easier use of Eq. (6a) by presenting $316 \cdot\left(\frac{T_{c}}{100}-\frac{T_{k}}{100}\right)^{1 / 4}$ as a polynomial with integer exponents. For example, an analysis shows that, in the case of operating temperature difference from $100^{\circ} \mathrm{C}$ to $110^{\circ} \mathrm{C}$ (in which a hot box solar collector operates), this factor can be written down (with sufficient accuracy) as polynomial of degree one:

$$
316 \cdot\left(\frac{T_{c}}{100}-\frac{T_{k}}{100}\right)^{1 / 4}=316 \cdot\left(\frac{T_{c}}{100}-\frac{T_{k}}{100}\right)+D
$$

Then Eq. (6) will look as follows:

$$
q_{b k}^{\prime}=A_{1}\left[316\left(\frac{T_{c}}{100}-\frac{T_{k}}{100}\right)+D\right]
$$


where $D$ is the tube diameter; the numerical values of specific heat $C$ (331 and 24.8) are true at $T_{k}-T_{c} \geq 5$ because

$$
q_{t o t}=q_{s t}+q_{s t}+q_{b k}+q_{b k}^{\prime}
$$

After substituting the values of summands $q_{s t}, q_{b k}$ and $q_{b k}^{\prime}$ to the right-hand side of Eq. (8) we obtain

$$
\begin{aligned}
q_{t o t} & =A\left[\left(\frac{T_{k}}{100}\right)^{4}+\left(\frac{T_{c_{1}}}{100}\right)^{4}-2\left(\frac{T_{c}}{100}\right)^{4}\right]+ \\
& \left.+A_{1} 316\left[\left(\frac{T_{k}}{100}-\frac{T_{c}}{100}\right)\right)\right]^{5 / 4}+q_{n k}
\end{aligned}
$$

or

$$
\begin{aligned}
q_{\text {tot }}=A\left[\left(\frac{T_{k}}{100}\right)^{4}+\left(\frac{T_{c_{1}}}{100}\right)^{4}-2\left(\frac{T_{c}}{100}\right)^{4}\right]+ \\
+A_{1} C\left[\left(\frac{T_{k}}{100}-\frac{T_{c}}{100}\right)\right]+A_{1} D+q_{n k} .
\end{aligned}
$$

Besides Eqs. (9) or (10) that determine $q_{t o t}$, an auxiliary equation has to be set up, for example, the heat transfer equation for water transfer from the outer surfaces of channels (tubes) to the liquid. If the average temperature of channel (tube) surfaces is $\bar{T}_{k}$ and that of the water in the channels of solar collector is $\bar{t}_{b}$, then the heat transfer equation for parallel channels is

$$
q_{\text {tot }}=\frac{\pi m\left(\bar{T}_{k}-\bar{T}_{b}\right)}{\frac{2.3}{2 A_{c}} \lg \frac{d}{d_{0}}+\frac{1}{a_{b} d_{0}}}=\frac{\pi \alpha\left(\bar{T}_{k}-\bar{T}_{b}\right)}{\frac{2.3}{2 \lambda_{k}} \lg \frac{d}{d_{0}}+\frac{1}{a_{b} d_{0}}}
$$

If it is impossible to neglect heat loss from the outer surfaces, then the total heat loss will be twice as much, and consequently a useful quantity of heat absorbed by water will be less. In this case, the total heat loss may be practically taken into account by the coefficient $\mathrm{x} 1$ :

$$
x_{1}=1-\frac{k_{b}}{k_{c}} \cdot \frac{F_{b}}{F_{c}}
$$

In other words, at joint solving the above equations, Eq. (11) should be replaced by

$$
q_{o n}=\left(1+\frac{k_{b}}{k_{c}} \cdot \frac{F_{b}}{F_{c}} q_{n}\right.
$$


where $F_{c}\left(F_{b}\right)$ is the solar collector surfaces without (with) glass.

Equations (7) and (13) have eight unknowns, namely, $q_{n k}, q_{n}, q_{t o t}, T_{k}, \bar{T}_{k}$, $T_{c_{1}}, T_{c_{2}}$ and Re. After such modification, Eq. (13) is

$$
q_{n}=\alpha_{2}\left(T_{c_{2}}-T_{0}\right)+4.9 E c\left[\left(\frac{T_{c_{2}}}{100}\right)^{4}-\left(\frac{T_{0}}{100}\right)\right]^{4} .
$$

When considering the set up equations, we see that they are quartic. To conveniently calculate analytical solution, let us try to reduce these equations to those of the first degree. Indeed, at normal solar collector operation $T_{k}, T_{c}$, $T_{c_{1}}$ and $T_{c_{2}}$ vary practically from $40^{\circ} \mathrm{C}$ to $100^{\circ} \mathrm{C}$, while the air temperature varies from $10^{\circ} \mathrm{C}$ to $50^{\circ} \mathrm{C}$. In such temperature ranges, the dependence $\left(\frac{T}{100}\right)^{4}$ can be expressed with sufficient accuracy as straight-line equation.

The following equation is true for the first four temperatures:

$$
\left(\frac{T}{100}\right)^{4}=M\left(\frac{T}{100}\right)+N=168\left(\frac{T}{100}\right)-438,
$$

for air

$$
\left(\frac{T_{0}}{100}\right)^{4}=R\left(\frac{T_{0}}{100}\right)+S=103\left(\frac{T_{0}}{100}\right)-227,
$$

One can see that the corresponding replacement of $T_{k}, T_{c}, T_{c_{1}}$ and $T_{c_{1}}$ by the expressions compiled in the form of Eq. (15) and of $T_{0}$ by the expressions compiled in the form of Eq. (16) reduces the above equations to those of the first degree that are solved in the ordinary way.

For approximate calculations that provide acceptable results, the computing method for solar collector can be simplified by supposing that

$$
\begin{aligned}
& T_{c_{1}}=C_{1} T_{k}+\left(1-C_{1}\right) T_{0} \\
& T_{c_{2}}=C_{2} T_{k}+\left(1-C_{2}\right) T_{0}
\end{aligned}
$$

The above equations can be obtained from the expressions for heat loss in the steady-state:

$$
q_{n} k_{c}\left(T_{k}-T_{0}\right)=\left(\alpha_{1}-\alpha_{l_{1}}\right)\left(T_{k}-T_{c_{1}}\right)=\frac{\lambda_{c}}{\delta_{c}}\left(T_{c_{1}}-T_{c_{2}}\right)=\left(\alpha_{2}-\alpha_{\lambda_{2}}\right)\left(T_{c_{2}}-T_{0}\right),
$$


where $\alpha_{l_{1}}$ is the factor of heat transfer from the surfaces of channels (tubes) and screen to the inner surface of glass; $\alpha_{l_{2}}$ is the heat-transfer factor taking into account radiation from the outer surface of glass to environment.

To prove that $T_{c_{1}}$ and $T_{c_{2}}$ can be presented as in Eqs. (17) and (18), let us divide Eq. (19) by $\left(\alpha_{1}+\alpha_{l_{1}}\right.$. Then

$$
\begin{aligned}
k_{0}=\left(T_{k}-T_{0}\right)=\left(T_{k}-T_{c_{1}}\right)=\frac{\alpha_{3}}{\alpha_{1}+\alpha_{l}}\left(T_{c_{1}}-T_{c_{2}}\right) & = \\
& =\frac{\alpha_{2}+\alpha_{l_{2}}}{\alpha_{1}+\alpha_{l_{2}}}\left(T_{c_{2}}-T_{0}\right)
\end{aligned}
$$

where $k_{0}=\frac{k_{c}}{\alpha_{1}+\alpha_{l_{1}}}$ and $\alpha_{3}=\frac{\lambda_{c}}{\delta_{c}}$. From Eq. (20) we find:

$$
T_{c_{1}}=C_{1} T_{k}+\left(1-C_{1}\right) T_{0}, T_{c_{2}}=C_{2} T_{k}+\left(1-C_{2}\right) T_{0},
$$

where $C_{1}=1-k_{0}$ and $C_{2}=k_{0} \frac{\alpha_{1}+\alpha_{l_{1}}}{\alpha_{2}+\alpha_{l_{2}}}$.

$T_{c_{1}}$ and $T_{c_{2}}$ may be presented using Eqs. (19) and (20); so further application of the above equations becomes possible if a method for determining numerical values of $C_{1}$ and $C_{2}$. They can be found by inserting the values of $T_{c_{1}}$ and $T_{c_{2}}$ :

$$
\left(\alpha_{1}+\alpha_{l_{1}}\right)\left(1-C_{1}\right)=\alpha_{3}\left(C_{1}-C_{2}\right)\left(\alpha_{2}+\alpha_{l_{1}}\right) C_{2}
$$

Then, substituting to Eq. (20) instead of Eq. (21) its value $\alpha_{\lambda_{1}}$ from Eq. (19), we obtain:

$$
\left[2\left(1-C_{1}\right)^{1 / 4} \cdot\left(T_{k}-T_{0}\right)^{1 / 4}+\alpha_{l_{1}}\right]\left(1-C_{1}\right)=\varepsilon_{3}\left(C_{1}-C_{2}\right)=C_{2}\left(\alpha_{1}+\alpha_{l_{2}}\right) .
$$

Because in the obtained set of equations with two unknowns $C_{1}<0.5$, $\left(1-C_{1}\right)$ can be written as

$$
\left(1-C_{1}\right)^{1 / 4}=1-\frac{C_{1}}{4}=1-0.25 C_{1} .
$$

Then, denoting $\left.T_{k}-T_{0}\right)^{1 / 4}$ by $x$ in Eq. (22) and taking into account the value of $(1 C 1)$ from Eq. (23), we can rewrite Eq. (23) as two equations with unknowns $C 1$ and $C 2$ :

$$
\left[2\left(1-0.25 C_{1}\right) x+\alpha_{l_{1}}\right]\left(1-C_{1}\right)=\alpha_{3}\left(C_{1}-C_{2}\right)
$$

and 


$$
\alpha_{3}\left(C_{1}-C_{2}\right)=\left(\alpha_{2}+\alpha_{l_{1}}\right) C_{2} .
$$

A joint solving this set of equations gives:

$$
C_{1}=\frac{2.5 x+\alpha_{l_{1}}+U-\sqrt{\left(2.5 x+\alpha_{l_{1}}+U\right)^{2}-2 x\left(2 x+\alpha_{l_{1}}\right)}}{x}
$$

and

$$
C_{2}=\frac{\alpha_{3}}{\alpha_{2}+\alpha_{l_{2}}+\alpha_{3}} \cdot C_{1}=Z_{c_{1}}
$$

where

$$
U=\frac{\alpha_{3}\left(\alpha_{3}+\alpha_{l_{2}}\right)}{\alpha_{2}+\alpha_{l_{2}}+\alpha_{3}}
$$

During operation of a hot box solar collector with single glazing, the value of $T_{k}-T_{c_{1}}$ varies from $40^{\circ} \mathrm{C}$ to $80^{\circ} \mathrm{C}$; this corresponds to $x$ variation from 2.5 to 3. An analysis of Eq. (26) shows that the above variation affects the $C 1$ value but slightly, so it is possible to enter the mean value $x=2.75$ into Eq. (26). Taking the mean value $\alpha_{l_{1}}=\alpha_{l_{2}}=5.3 \mathrm{~W} / \mathrm{m}^{2} \mathrm{~K}$, one can rewrite Eq. (26) as

$$
C_{1}=4.8+0.363-\sqrt{(4.8+0.36 U)^{2}-8.6} .
$$

As the thickness of solar collector glass is varied from $2.5 \mathrm{~mm}$ to $4 \mathrm{~mm}$ at $\lambda_{c}=0.64 \mathrm{~W} / \mathrm{m}^{2} \mathrm{~K}$, the numerical values of coefficients $U$ and $Z$ slightly depend on $\delta$, but they depend to a greater extent on $\alpha_{2}$ and wind speed $V_{b}$.

Table 2. Dependence of numerical values of coefficients on the wind speed.

\begin{tabular}{|c|c|c|c|c|c|c|}
\hline$V_{b}$ & 1 & 2 & 3 & 4 & 5 & \\
\hline$a_{1}$ & 586 & 636 & 681 & 706 & 747 & $a_{1}=\left(100 a_{2}+4.9 \varepsilon_{c m} M\right) C_{2}$ \\
\hline$a_{2}$ & 288 & 338 & 383 & 408 & 449 & $a_{2}=a_{1}+4.9 \varepsilon_{c m}(R M)$ \\
\hline$a_{3}$ & 968 & 968 & 968 & 968 & 968 & $a_{3}=4.9 \varepsilon_{c m}(S N)$ \\
\hline
\end{tabular}

Similarly, the equation can be transformed by substituting the $T_{c_{1}}$ values:

$$
q_{t o t}=\left(a_{4}^{\prime}+a_{4}^{\prime \prime}\right) \frac{T_{k}}{100}+a_{5} \frac{T_{0}}{100}-a_{6} \frac{T_{c}}{100}+a_{7}+q_{n k}
$$

where $a_{4}^{\prime}=A M\left(1-C_{1}\right) a_{6}=2 M A+A_{1} C, a_{4}^{\prime \prime}=A_{1} C a_{7}=A_{1} D$ and $a_{5}=M A\left(1-C_{1}\right) q_{b k}=E_{1} a_{c} \xi \varepsilon_{k} \phi$. 
Shown in Table 3 are numerical values of the coefficients $a_{4}^{\prime}, a_{4}^{\prime \prime}, a_{5}, a_{6}$, and $a_{7}$ as functions of $\phi$ and $d$. It will be recalled that the initial relations were derived on the assumption that the area $F_{c}$ of solar collector surface is $1 \mathrm{~m}^{2}$ and the coefficients of light area of glass $\left(\eta_{\phi}\right)$ and direct solar radiation absorbed by the surfaces of channels (tubes) $\left(\eta_{\phi}\right)$ are equal to unity.

To move to thermal design of solar collectors with total surface area of 10 $\mathrm{m}^{2}$ by calculating $1 \mathrm{~m}^{2}$ of the total glass surface area, the right-hand side of expression for $q_{n g}$ should be multiplied by $\eta_{c}$ and expression for $q_{n k}$ in Eq. (27) should be multiplied by $\eta_{c} \eta_{\phi}$. To take into account heat loss through the side face, the right-hand side of expression for $q_{n}$ should be multiplied by $x_{1}$ from (a). Then

$$
\begin{gathered}
q_{n g}^{\prime}=\eta_{c} q_{n g} \\
q_{t o t}^{\prime}=q_{t o t}-q_{n k}\left(1-\eta_{c} \eta_{\phi}\right) \\
q_{o n}=x_{1} q_{n}
\end{gathered}
$$

The coefficient $\eta_{c}$ in Eqs. (30) and $(31)$ is the ratio between the light $\left(F_{c . c}\right)$ and total $\left(F_{c}\right)$ areas of glass covering of solar collector $\left(F_{c . c}\right)$ i.e., the surface without accounting for sash shading):

$$
\eta_{c}=\frac{F_{c . c}}{F_{c}}=1-\frac{F_{c m}}{F_{c}}
$$

Here $F_{c . c}$ is the difference between the total glass area $F_{c}$ and shadow area $F_{c m}$. The latter depends on the altitude of the sun over the horizon and structural dimension of the solar collector. $F_{c m}$ can be tentatively calculated from the expression

$$
F_{c m}=\left(a_{0}+c\right)\left[S\left(e-u a_{0}\right)\right]+c\left(l-u a_{0}+b_{0}\right)
$$

where $u$ is the number of cross strips of section $a_{0} x\left(c+b_{0}\right), m ; a_{0}(c$ and $b)$ are the $X-(Y-)$ dimensions of strips, $m ; S$ is the number of longitudinal (continuous) strips; $l$ is the solar collector length, $m$.

The coefficient $\eta_{\phi}$, that is the ratio of a sum of the illuminated screen area and area of projection of the illuminated surface of channels (tubes) $F_{c b}$ to the total screen area $F_{o k}$ is determined similarly. It is a function of the altitude of the sun over the horizon, height of solar collector $H$ and structural dimension of the solar collector. Since $F_{o k}=F_{c}$, 
Table 3. Dependences of numerical values of the coefficients $a_{4}^{\prime}, a_{4}^{\prime \prime}, a_{5}, a_{6}$ and $a_{7}$ on $\phi$ and $d$.

\begin{tabular}{|c|c|c|c|c|c|c|c|c|c|c|}
\hline$\phi$ & 0 & 0.08 & 0.13 & 0.18 & 0.23 & 0.28 & 0.33 & 0.38 & 0.43 \\
\hline \multicolumn{8}{|c|}{$V_{b}(m / s) a_{4}^{\prime}=A M\left(1-C_{1}\right)(a)$} \\
\hline 1 & 0 & 72.7 & 192 & 326 & 495 & 688 & 892 & 1112 & 1353 \\
\hline 2 & 0 & 67.8 & 185 & 315 & 478 & 665 & 862 & 1074 & 1308 \\
\hline 3 & 0 & 66.2 & 181 & 308 & 467 & 649 & 841 & 1049 & 1276 \\
\hline 4 & 0 & 64.7 & 177 & 301 & 456 & 635 & 823 & 1026 & 1248 \\
\hline 5 & 0 & 63.9 & 175 & 297 & 451 & 627 & 813 & 1013 & 1233 \\
\hline \multicolumn{8}{|c|}{$D a_{4}^{\prime \prime}=A_{1} C(b)$} \\
\hline$d_{\text {eff }} / \phi$ & 0 & 0.08 & 0.13 & 0.18 & 0.23 & 0.28 & 0.33 & 0.38 & 0.43 \\
\hline 8 & 0 & 54 & 88 & 122 & 156 & 190 & 224 & 259 & 293 \\
\hline 13 & 0 & 48 & 78 & 108 & 138 & 168 & 198 & 229 & 258 \\
\hline 18 & 0 & 45 & 74 & 99 & 131 & 155 & 182 & 210 & 238 \\
\hline 23 & 0 & 41 & 69 & 93 & 119 & 145 & 173 & 197 & 224 \\
\hline 28 & 0 & 39 & 64 & 89 & 114 & 138 & 170 & 188 & 213 \\
\hline 33 & 0 & 38 & 62 & 86 & 109 & 134 & 181 & 181 & 205 \\
\hline 38 & 0 & 37 & 59 & 83 & 105 & 129 & 152 & 175 & 198 \\
\hline 43 & 0 & 35 & 57 & 80 & 102 & 125 & 147 & 169 & 192 \\
\hline \multicolumn{8}{|c|}{$V_{b}(m / s) a_{5}=M A\left(1-C_{1}\right)(c)$} \\
\hline$\phi$ & 0 & 0.08 & 0.13 & 0.18 & 0.23 & 0.28 & 0.33 & 0.38 & 0.43 \\
\hline 1 & 0 & 20.5 & 56 & 145 & 95 & 201 & 260 & 325 & 396 \\
\hline 2 & 0 & 23 & 62 & 161 & 106 & 224 & 291 & 363 & 442 \\
\hline 3 & 0 & 24 & 67 & 173 & 114 & 240 & 312 & 389 & 473 \\
\hline 4 & 0 & 26 & 71 & 183 & 121 & 255 & 330 & 412 & 501 \\
\hline 5 & 0 & 27 & 73 & 188 & 124 & 262 & 340 & 424 & 516 \\
\hline \multicolumn{8}{|c|}{$d_{e f f} m m a_{6}=2 M A+A_{1} C(d)$} \\
\hline 8 & 0 & 0.08 & 0.13 & 0.18 & 0.23 & 0.28 & 0.33 & 0.38 & 0.43 \\
\hline 8 & 0 & 145 & 302 & 545 & 796 & 1080 & 1379 & 1679 & 2043 \\
\hline 13 & 0 & 139 & 296 & 531 & 778 & 1058 & 1353 & 1667 & 2008 \\
\hline 18 & 0 & 136 & 293 & 522 & 771 & 1045 & 1337 & 1648 & 1988 \\
\hline 23 & 0 & 132 & 289 & 516 & 760 & 1035 & 1326 & 1635 & 1974 \\
\hline 28 & 0 & 130 & 287 & 512 & 754 & 1029 & 1326 & 1626 & 1963 \\
\hline 33 & 0 & 128 & 286 & 509 & 749 & 1024 & 1312 & 1619 & 1955 \\
\hline 38 & 0 & 127 & 285 & 505 & 745 & 1019 & 1307 & 1613 & 1948 \\
\hline 43 & 0 & 126 & 283 & 503 & 742 & 1015 & 1302 & 1607 & 1942 \\
\hline$\phi$ & 0 & 0.08 & 0.13 & 0.18 & 0.23 & 0.28 & 0.33 & 0.38 & 0.43 \\
\hline 8 & 0 & -4.06 & -6.6 & -9.1 & -11.7 & -14.2 & -16.8 & -19.4 & -21.9 \\
\hline 13 & 0 & -3.6 & -5.8 & -8.1 & -10.3 & -12.6 & -14.3 & -17.1 & -19.3 \\
\hline \multicolumn{8}{|c|}{$d_{e f f} a_{7}=A_{1} C(e)$} \\
\hline
\end{tabular}

$$
\eta_{\phi}=\frac{F_{c b}}{F_{o k}}=\frac{F_{c b}}{F_{c}}=1-\frac{F_{m k}}{F_{c}}
$$




\begin{tabular}{|l|l|l|l|l|l|l|l|l|l|}
\hline 18 & 0 & -3.4 & -5.5 & -7.4 & -9.8 & -11.6 & -13.6 & -15.7 & -17.8 \\
\hline 23 & 0 & -3.1 & -5.0 & -6.9 & -8.9 & -10.8 & -12.8 & -14.7 & -16.7 \\
\hline 28 & 0 & -2.9 & -4.8 & -6.7 & -8.5 & -10.4 & -12.7 & -14.1 & -15.9 \\
\hline 33 & 0 & -2.8 & -4.6 & -6.4 & -8.2 & -10.0 & -11.7 & -13.6 & -15.4 \\
\hline 38 & 0 & -2.7 & -4.4 & -6.2 & -7.9 & -9.6 & -11.3 & -13.1 & -14.8 \\
\hline 43 & 0 & -2.6 & -4.3 & -6.0 & -7.6 & -9.3 & -11.0 & -12.6 & -14.3 \\
\hline
\end{tabular}

where $F_{m k}$ is the difference between the total area (the open part of absorber) and $F_{c b}$. It can be tentatively calculated from the following expression:

$$
F_{m k}=(H+C+f)\left[(S+1)\left(b-u a_{0}\right)+b\right]+\left[a_{0}+\left(c+b_{0}\right)\right] u b,
$$

where $f$ is the distance from the vertical walls of solar collector to the inner edge of sash, $m$.

The factor in $x_{1}$ may be calculated as follows. Supposing that there is no heat loss from the lateral surface, $q_{n}$ and temperature conditions of solar collector are determined from the following expressions:

$$
\begin{gathered}
q_{n g}^{\prime}=\eta_{c} q_{n g}=q_{t o t}^{\prime}+q_{n}, \\
q_{t o t}^{\prime}=q_{t o t}-\left(1-\eta_{c} \eta_{\phi}\right) q_{n k} .
\end{gathered}
$$

Then $K_{c}$ is found, supposing that it depends on $T_{k}$ but slightly over the operating temperature range. This means that $K_{c}$ calculated without allowance for heat loss from the lateral surface slightly differs from the real $K_{c}$ value (with allowance for heat loss from the lateral surface). The calculation is performed using the following expression:

$$
K_{c}=\frac{q_{n}}{T_{k}-T_{0}}
$$

The total thermal resistance of glass and lateral surface of solar collector is a sum thermal resistances of radiation, convection and heat conduction:

$$
\begin{aligned}
& \frac{1}{K C}=R_{\lambda k}+R_{c}, \\
& \frac{1}{K_{b}}=R_{\lambda_{1} k_{1}}+R_{b} .
\end{aligned}
$$


Here $R_{\lambda k} \approx R_{\lambda_{1} k_{1}}$ is the total radiation and convection resistance: $R_{\lambda}$ and $R_{b}$ are the heat resistance of glass and lateral surface of solar collector, respectively. It is rather easy to get $\frac{K_{b}}{K_{c}}$ by supposing that $R_{\lambda k} \approx R_{\lambda_{1} k_{1}}$ :

$$
\frac{K_{b}}{K_{c}}=\frac{1}{1+\left(R_{b} \pm R_{c}\right) K_{c}} .
$$

Having the $\frac{K_{b}}{K_{c}}$ values, we determine $F_{b}$ and $F_{c}$ taking into account that a solar collector is a rectangular parallelepiped $H \times b \times l$. Indeed,

$$
\begin{gathered}
F_{b}=b l+2 l H+2 b H \\
F_{c}=b c
\end{gathered}
$$

Therefore,

$$
\frac{F_{b}}{F_{c}}=1+2 H\left(\frac{1}{C}+\frac{1}{b}\right) .
$$

If heat loss through the solar collector bottom are low and can be neglected, then

$$
\frac{F_{b}}{F_{c}}=2 H\left(\frac{1}{l}+\frac{1}{b}\right) .
$$

A working equation for determination of coefficient $X_{1}$ is obtained by substituting $\frac{K_{b}}{K_{c}}$ from Eq. (41) and $\frac{F_{b}}{F_{c}}$ from Eq. (44) into expression Eq. (45):

$$
X_{1}=1+\frac{2 H\left(\frac{1}{l}+\frac{1}{b}\right)}{1+\left(\sum \frac{\delta}{\lambda}-\frac{\delta_{c}}{\lambda_{c}}\right) K_{c}} .
$$

So the working equations used to tentatively design a solar collector are as follows:

$$
\begin{gathered}
q_{n g}^{\prime}=q_{\text {tot }}^{\prime}+q_{o n}=q_{n g} \eta_{c} \\
q_{o n}=x q_{n}=x\left(a_{1} \frac{T_{k}}{100}-a_{2} \frac{T_{0}}{100}-a_{3}\right) \\
q_{t o t}^{\prime}=q_{t o t}-\left(1-\eta_{c} \eta_{\phi}\right) q_{n k}=\left(q_{4}^{\prime}+a^{\prime}\right) \frac{T_{k}}{100}+a_{5} \frac{T_{0}}{100}-a_{6} \frac{T_{c}}{100}+a_{7}+q_{n k}^{\prime},
\end{gathered}
$$


where $q_{n k}=\eta_{c} \eta_{\phi} \eta_{n k}=E \perp a_{c m} \varepsilon_{k} \eta_{c} \eta_{\phi} \phi$.

The order of solving the above equations is as follows. At first, the equations (I), (II) and (III) are solved assuming that $X=1$. This makes it possible to determine the coefficients $K_{c}$ (and consequently $X$ ). After this resolving these equations enables one to calculate $q_{\text {tot }}^{\prime}$, $q_{\text {tot }}$ and thermal efficiency $\eta$ of solar collector that are close to real ones. The results of calculations (with regard to heat loss) at $q_{n g}^{\prime}=397 \mathrm{~W}, t_{i n}^{w}=17^{\circ} \mathrm{C}$ and $V_{b}=3 \mathrm{~m} / \mathrm{s}$ are presented as functions of $\phi$, with $d_{e q}=23 \mathrm{~mm}$ and $t_{\text {out }}^{w}=60^{\circ} \mathrm{C}, 70^{\circ} \mathrm{C}$ and $80^{\circ} \mathrm{C}$ in Tables 4 and 5 .

Table 4. Dependence of energy data of flat plate solar collectors on $\phi$ at $V=2 \mathrm{~m} / \mathrm{s}, V=3 \mathrm{~m} / \mathrm{s}$ and $t_{h w}=60^{\circ} \mathrm{C}$.

\begin{tabular}{|c|c|c|c|c|c|c|c|c|c|}
\hline$\phi$ & 0 & 0.08 & 0.13 & 0.18 & 0.23 & 0.28 & 0.33 & 0.38 & 0.43 \\
\hline \multicolumn{8}{|c|}{$d_{e q}=23 m m, t_{h w}=60^{\circ} C, V=3 m / s$} \\
\hline$t_{k}$ & 0 & 105 & 83 & 77 & 77 & 71 & 66 & 61 & - \\
\hline$\eta, \%$ & 0 & 18 & 37 & 42 & 52 & 52 & 65 & 68 & - \\
\hline $\operatorname{Re}$ & 0 & 2.5 & 4.8 & 5.5 & 6.8 & 7.7 & 8.5 & 9.0 & - \\
\hline$q_{\text {tot }}$ & 0 & 103 & 207 & 238 & 291 & 333 & 364 & 385 & - \\
\hline \multicolumn{8}{|c|}{$d_{e q}=23 m m, t_{h w}=60^{\circ} C, V=2 m / s$} \\
\hline$\phi$ & 1.1 & & 0.55 & & 0.36 & & 0.27 & & 0.22 \\
\hline$t_{k}$ & & & 55 & & 64 & & 68 & & \\
\hline$\eta, \%$ & & & 0.82 & & 0.68 & & 0.64 & & \\
\hline $\operatorname{Re}$ & & & 10.8 & & 8.9 & & 8.4 & & \\
\hline$q_{\text {tot }}$ & & & 463 & & 381 & & 359 & & \\
\hline
\end{tabular}

\section{Conclusion}

One can see from Tables 4 and 5 that the following items are to be complied when designing a flat plate solar collector:

1) At a specified efficient diameter of channel, thermal efficiency of a plant grows as $\phi$ (the ratio of the channel diameter to the distance between channel axes) increases. The upper limit of $\phi$ is restricted by the given temperature of heated water output. It reaches its peak at $t_{k}=t_{\text {out }}^{w}$ because $q_{n k}^{\prime}>>q_{c n}\left(q_{n k}^{\prime}\right.$ is the output heat flow and $q_{c n}$ is the input heat flow).

2) All other factors being the same, the thermal efficiency of the plant is reduced but slightly as channel diameter grows from $14 \mathrm{~mm}$ to $30 \mathrm{~mm}$. The effect becomes stronger as channel diameter is decreased below $14 \mathrm{~mm}$. 
Table 5. Dependence of energy data of flat plate solar collectors on $\phi$ at $t_{h w}=70^{\circ} \mathrm{C}$ and $t_{h w}=80^{\circ} \mathrm{C}$.

\begin{tabular}{|c|c|c|c|c|c|}
\hline \multicolumn{7}{|c|}{$d_{e q}=23 \mathrm{~mm}, t_{h w}=70^{\circ} \mathrm{C}$} \\
\hline$\phi$ & 1.1 & 0.55 & 0.36 & 0.27 & 0.22 \\
\hline$t_{k}$ & 0 & 105 & 83 & 77 & 77 \\
\hline$\eta, \%$ & 0 & 18 & 37 & 42 & 52 \\
\hline $\operatorname{Re}$ & 0 & 2.5 & 4.8 & 5.5 & 6.8 \\
\hline$q_{\text {tot }}$ & 0 & 103 & 207 & 238 & 291 \\
\hline \multicolumn{7}{|c|}{$d_{e q}=23 m m, t_{h w}=80^{\circ} \mathrm{C}$} \\
\hline$\phi$ & 1.1 & 0.55 & 0.36 & 0.27 & 0.22 \\
\hline$t_{k}$ & & 64 & 67 & 79 & \\
\hline$\eta, \%$ & & 65 & 63 & 49 & \\
\hline $\operatorname{Re}$ & & 8.45 & 8.1 & 6.4 & \\
\hline$q_{\text {tot }}$ & & 363 & 350 & 273 & \\
\hline
\end{tabular}

3) As water temperature is decreased at the plant output, the thermal efficiency is increased and shifts toward growing $\phi$ values.

4) Under the normal operating conditions of a flat plate solar collector, the maximum practically achievable value of thermal efficiency at $t=60^{\circ} \mathrm{C}$ is 0.28 , and it grows to 0.4 as the temperature of output water is reduced by $10^{\circ} \mathrm{C}$.

\section{References}

[1] D. Nolte, Strong, Europe's Buildings Under the Microscope, A Country-by-country Review of the Energy Performance of Building, Buildings Performance Institute Europe (BPIE) (2011).

[2] C.A. Balaras, K. Droutsa, E. Dascalaki, S. Kontoyiannidis, Deterioration of European apartment buildings, Energy Build, No. 37 (2005), 515-527.

[3] I.A. Kapitonov, A.A. Shulus, M.V. Simonova, D.A. Sviredenko, R.T. Shreyner, Green Energy Revolution Perspectives in Modern Russian Economy, International Journal of Economic Perspectives, Vol. 3, No. 10, (2016), 166-175.

[4] Bergmann, Faade integration of solar thermal collectors - a new opportunity for planners and architects, Renew Energy World, No. 5 (2002), 89-97.

[5] A.G. Hestnes, Building integration of solar energy systems, Sol. Energy, No. 67 (2000), 181-187. http://dx.doi.org/10.1016/S0038-092X(00) 00065-7.

[6] M. Munari Probst, C. Roecker, Towards an improved architectural quality of building integrated solar thermal systems (BIST), Sol. Energy, No. 81 (2007), 1104-1116. http://dx.doi.org/10.1016/j.solener.2007.02.009.

[7] IEA SHC Task 41 (2012). Retrieved from http://task41.iea-shc.org/. 
[8] Solabs (2006). SOLABS. Development of unglazed solar absorbers (resorting to coloured selective coatings on steel material) for building facades, and integration into heating systems (solabs) - Project reference: ENK6-CT-2002-00679. Retrieved from http://cordis.europa.eu/project/rcn/67210_en.html.

[9] Bionicol (2011). BIONICOL - Project final report. Retrieved from www.bionicol.eu.

[10] J.A. Duffie, W.A. Beckman, Solar Engineering of Thermal Processes, Wiley, Hoboken, NJ (2006). 
